\title{
Expression profiling and local adaptation of Boechera holboellii populations for water use efficiency across a naturally occurring water stress gradient
}

\author{
CHARLES A. KNIGHT HEIKOVOGEL JUERGEN KROYMANN ALICESHUMATE \\ HANNEKE WITSENBOER and THOMAS MITCHELL-OLDS
}

\begin{abstract}
We studied the physiological basis of local adaptation to drought in Boechera holboellii, a perennial relative of Arabidopsis thaliana, and used cDNA-AFLPs to identify candidate genes showing differential expression in these populations. We compared two populations of B. holboellii from contrasting water environments in a reciprocal transplant experiment, as well as in a laboratory dry-down experiment. We continuously measured the water content of soils using time domain reflectometery (TDR). We compared populations for their water use efficiency (WUE), root/shoot ratios (R:S) and leaf mass per unit area (LMA) in the field and in the laboratory, and identified candidate genes that (i) responded plastically to water stress and (ii) were differentially expressed between the two populations. Genotypes from the drier site had higher WUE, which was attributable to a large reduction in transpirational water loss. The xeric-adapted population also had increased investment in root biomass and greater leaf mass per unit area. Reciprocal transplants in the field had significantly greater survival in their native habitat. In total, $450 \mathrm{cDNA}-\mathrm{AFLP}$ fragments showed significant changes between drought and control treatments. Furthermore, some genes showed genotype (population)-specific patterns of up- or down-regulation in response to drought. Three hundred cDNA-AFLP bands were sequenced leading to the identification of cDNAs coding for proteins involved in signal transduction, transcriptional regulation, redox regulation, oxidative stress and pathways involved in stress adaptation. Some of these proteins could contribute a physiological advantage under drought, making them potential targets for natural selection.
\end{abstract}

Keywords: Arabidopsis, Boechera, drought tolerance, local adaptation, transcription profiling

\section{Introduction}

Water availability is a primary factor limiting the distribution and abundance of plants. Understanding the mechanisms of how plants cope with water stress has been a central topic in plant physiology for decades (Shrantz \& Piemesal 1927; Stebbins 1952; Bohnert et al. 1995; Bray 1997). With the recent advent of ecological genomics (Feder \& MitchellOlds 2003; Thomas \& Klaper 2004), it is now feasible to study changes in gene expression controlled by water availability, and to positionally clone the loci responsible for adaptation to drought stress. Although Arabidopsis genomics has enabled enormous progress towards the first goal (Abe et al. 2003; Boyce et al. 2003; Cheong et al. 2003; Mckay et al. 2003; Oono et al. 2003), Arabidopsis species are confined to mesic environments, and therefore provide limited information on the evolution of drought tolerance. 
In contrast, closely related species in the genus Boechera are adapted to mesic, xeric, and alpine habitats (Rollins 1993; Mitchell-Olds 2001) and display a wide range of adaptive variation for drought tolerance (McKay et al. 2001). These species provide an opportunity to identify genes that are responsive to drought both plastically and evolutionarily.

The onset of water stress induces short-term changes in gene expression which can be studied using genomic methods such as transcription profiling or cDNA-AFLPs (complementary DNA-amplified fragment length polymorphism) (Kreps et al. 2002; Chaves et al. 2003; Oono et al. 2003; Kawaguchi et al. 2004; Rizhsky et al. 2004; Bartels \& Sunkar 2005). Arabidopsis studies have been reviewed by Bray (2004), who categorized induced genes in the areas of metabolism, transporters, signal transaction, transcription, heat-soluble hydrophilic, and unknown genes. Droughtregulated loci may also be induced by abscisic acid, salt or low-temperature stress, as well as wounding and herbivory (Reymond et al. 2000; Bray 2004). Transgenic experiments could verify the causal role of these induced genes in plant responses to drought (e.g. Oh et al. 2005). However, these experiments are rarely feasible for plants with interesting ecological attributes. Therefore, here we begin with a comparative approach where we 'ask the plant' which genes are differentially expressed.

Physiological responses to drought can be studied in a controlled environment where drought is artificially induced, as well as with reciprocal transplant experiments in the field (Harlan \& Martini 1938; Clausen \& Heisey 1958; Schemske 1984; Jordan 1991; Nagy 1997). Here we use both approaches to study ecotypic variation between populations of Boechera holboellii that naturally grow in quite different water environments ( Fig. 1). The simplest metric of

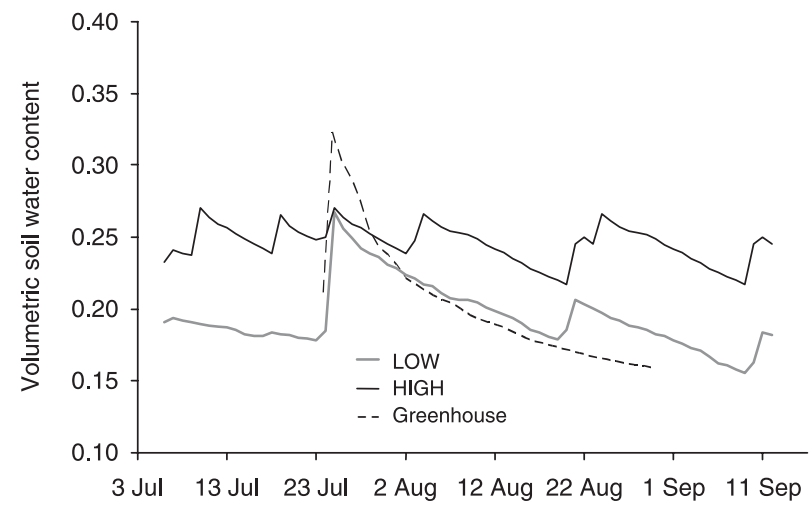

Fig. 1 Volumetric soil water content, measured by 10 TDR probes at the HIGH and LOW field sites. Data are from 3 July to 11 September 2002. The dashed line represents TDR probe data from the 29-day dry-down experiment in the laboratory. Notice the similarity in the rate of water loss between our dry-down experiment and what is commonly observed in the field. drought tolerance that can be gleaned from these experiments is survival. To better understand the physiological basis for differences in survival we also measured water use efficiency (WUE), root/shoot ratios (R:S), and leaf mass per unit area (LMA), which have all been used as indicators of drought tolerance. Here we define drought as the recurring limitation of water for extended periods during some part of the growing season rather than the other common use of the word that reflects abnormally dry periods on a decadal scale.

The ratio between photosynthesis and transpiration, commonly referred to as WUE, is a useful metric for determining a plant's strategy for dealing with drought (Raschke 1976; Carlson 1980; Fitter \& Hay 2002). Droughttolerant species typically have higher WUE if they lack deep roots that can access water during the dry period. This can be partially attributed to the fact that xerophytes typically have smaller, thicker leaves, giving a higher ratio of photosynthetic mesophyll to transpiring leaf area, compared to mesophytes (Abrams et al. 1994). Drought avoiders typically have lower WUE, grow fast and set seed before the onset of drought. WUE can be calculated either instantaneously (as we do here using a gas exchange system) or by biomass harvests after measured irrigation. Clearly, variation for WUE may influence the distribution and abundance of species along moisture gradients. We expect that dry environment, locally adapted genotypes of B. holboellii will have higher WUE than populations from more mesic habitats.

In addition to effects on WUE, species with small thick leaves have altered biophysical properties which tend to reduce heat load (Nobel 1974; Givnish 1979; Fitter \& Hay 2002). Furthermore, drought-tolerant plants cannot rely on turgor pressure to maintain leaf structure, and therefore often have an increased investment in the biomechanical support of leaves (Wright \& Cannon 2001). This combination of factors leads to increased investment in LMA. Large comparative analyses suggest that LMA is closely related to photosynthetic and transpiration rates (Wright et al. 2004) and a variety of other plant physiological traits. Leaves with higher LMA typically have higher WUE (Wright et al. 2004). Therefore, one avenue towards altering WUE may involve selection acting on leaf anatomy. Species with high LMA typically have smaller, thicker leaves, although it should be noted that plants with large leaves can have high LMA in some cases. We expect that in dry environments, locally adapted genotypes of B. holboellii will have higher LMA than populations from more mesic habitats.

Drought-tolerant species typically have higher rootto-shoot ratios (R:S), especially if they are perennial (Fitter \& Hay 2002). Plants that grow in drought-prone environments must develop deep root systems quickly in order to survive the drought. B. holboellii is perennial and often 
grows in water-limited environments, and we expect that in dry environment, locally adapted genotypes of $B$. holboellii will have higher R:S than populations from more mesic habitats.

\section{Methods}

\section{Species biology}

Genus Boechera (formerly Arabis) is a member of the Arabidopsis alliance (Mitchell-Olds et al. 2005), a monophyletic group that includes Boechera, Capsella, Halimolobos, Turritus, and species formerly classified within Arabidopsis, such as Crucihimalaya and Olimarabidopsis. Multilocus phylogenetic analysis (Oyama \& Mitchell-Olds, unpublished) shows that all of these genera are equidistant from Arabidopsis. More than 50 Boechera species are widely distributed across North America (Al-Shehbaz 2003), where they are adapted to a broad range of desert, mesic, and alpine environments (Rollins 1993). More than 15 laboratories in North America and Europe are researching many aspects of Boechera biology, providing fundamental information on ecology, evolution, and genetics of these species (Rollins 1993; Hamilton \& Mitchell-Olds 1994; Roy 1996, 2001; McKay et al. 2001; Mitchell-Olds 2001; Sharbel \& Mitchell-Olds 2001; Koch et al. 2003; Taskin et al. 2003; Dobes et al. 2004a, b; Sharbel et al. 2004; Schranz et al. 2005).

Boechera holboellii is found across much of North America, and is especially common in the western USA (Dobes et al. 2004a, b). It is a short-lived perennial ranging from xeric grasslands to subalpine meadows, spanning an elevation gradient $>2000 \mathrm{~m}$ in the northern Rocky Mountains (Mitchell-Olds, personal observation). The breeding system can be either apomictic or predominantly inbreeding (Schranz et al. 2005). Apomictic genotypes are diploid or triploid, while sexual individuals are diploid.

\section{Field sites}

We studied B. holboellii populations growing in the mountain ranges surrounding the Salmon River near Shoup, Idaho, in the Salmon-Challis National Forest. Two field sites were selected that differed considerably for water availability (see Fig. 1). We measured water availability at these field sites and in our common garden experiments using time domain reflectometry (TDR). TDR is based on the change in dielectric constant of the soil with changes in soil moisture, and provides a quantitative indicator of volumetric soil water content (Rhoades et al. 1976, 1989). For our study, we used Campbell Scientific (Logan) CS616 TDR probes that were $33 \mathrm{~cm}$ long. To ensure similar soil composition at each site and to protect TDR probes from damage during emplacement, we first removed surrounding soil from each probe location, then added sifted rock-free soil using a 1-cm wire mesh. These TDR probes were sampled by a Campbell Scientific CR10X datalogger and AM25T multiplexer. Because temperature can affect TDR measurements, we averaged midnight TDR measurements and compared these to noon TDR measurements on the previous day and the next day. Across all sampling days, we found that diurnal (temperature-related) fluctuations accounted for less than $10 \%$ of the absolute magnitude of TDR responses.

We choose two field sites with drastically different water availabilities. The dry site was located near Trail Creek, a tributary of Panther Creek and the Salmon River (henceforth the 'LOW' population). Vegetation on this steep south-facing slope at $1075 \mathrm{~m}$ includes bunch grasses and a few ponderosa pine and sagebrush. The cooler and wetter 'HIGH' site was at $2525 \mathrm{~m}$ on the south-facing slope of Bear Ridge near Long Tom Mountain, among lodgepole pine, Douglas fir, and sagebrush. These populations are $26 \mathrm{~km}$ apart and differ by $1450 \mathrm{~m}$ in elevation.

\section{Common environment dry-down experiment}

We compared genotypes (families) from the LOW and HIGH field sites. We grew these lines for two generations in a common environment to remove maternal effects. For the common garden experiment we compared nine $\mathrm{HIGH}$ families and six LOW families (accessions BR2, BR3, BR5, BR6, BR7, BR69, BR74, BR75, BR78, BR79 for the HIGH population, and TC50, TC51, TC52, TC54, TC55, TC56 for the LOW population). In this experiment, approximately 15 individuals survived from each family, for a total of 90 LOW plants and 135 HIGH plants.

We grew these plants in a sand/loam mix that mimicked soil composition at the LOW and HIGH field sites. We germinated seeds on moist filter paper in Petri dishes after a 2-week cold stratification at $4{ }^{\circ} \mathrm{C}$. Plants were then transferred to $15-\mathrm{cm}$ diameter, $0.5-\mathrm{m}$ PVC tubes filled with the soil mixture. We chose this growth environment to ensure that root systems would have adequate volume for development. Plants were grown in a randomized block design and rotated every 2 weeks. The plants were grown inside a large growth chamber under artificial lighting (fluorescent tubes with 400 PFD) on a $16 \mathrm{~h}$ day/ $8 \mathrm{~h}$ night cycle. After 4 months, WUE was measured for all plants. We then imposed a 29-day gradual dry-down without watering. Our observations showed that when using our soil and growth tubes, simply withholding water closely mimicked natural dry-down conditions in the field after precipitation pulses (see Fig. 1). Therefore, we infer that this dry-down experiment is a realistic test for how plants respond to water limitation in the field. WUE was measured approximately every 3 days for 29 days to capture the relative change in WUE between populations in response to drought. WUE was sampled on nine different days. 


\section{Reciprocal transplant experiment}

We compared genotypes (families) from the LOW and HIGH field sites. We grew these lines for two generations in a common environment to remove maternal effects. Plants were grown in 'cone-tainers' in a nearby greenhouse (Bitterroot Restoration, Inc.). Germination and survival were poor; hence, only 20 individuals were available from the LOW population, and approximately 120 individuals from the HIGH population. These plants were randomly divided into two groups of $10 \mathrm{LOW}$ plants and $60 \mathrm{HIGH}$ plants. These plants were transplanted to the field in a randomized design at each field site in June 2003. In the first week after transplanting we watered the plants to ameliorate the transplant effects.

\section{Traits}

WUE. We measured instantaneous WUE with a LI-COR 6400 portable gas exchange system (Lincoln). We used the LI-COR Arabidopsis leaf chamber with internal $\mathrm{CO}_{2}$ set to $360 \mathrm{mg} / \mathrm{g}$. In the laboratory we used a high intensity metal halide light source suspended $0.45 \mathrm{~m}$ above the leaf chamber. Under these conditions, light measured near the chamber was $400 \mu \mathrm{mol} \mathrm{m}^{-2} \mathrm{~s}^{-1}$ and heating of the leaf was negligible. Light response curves indicated that this light level was near saturating for the test plants. We used ambient light in the field and only measured on sunny days. We took three 1-min average measurements for each sampled leaf. For our analyses we used only the measurement that averaged during the second minute because we found that the chamber did not equilibrate until that point in the measurement cycle. In our laboratory dry-down experiment, we measured three randomly selected individuals of each family (six LOW or nine HIGH) on each sampling day. In the field we measured every surviving individual in August 2003, in a similar manner to the laboratory drydown experiment. WUE was measured in the field and in the laboratory between 9:00 $\mathrm{h}$ and 13:00 $\mathrm{h}$ using mature fully expanded leaves. In most cases the leaf occupied the entire leaf chamber, but when it did not, we corrected our measurements to calculate WUE using the proper area.

LMA. We measured leaf mass per unit area (LMA) using a $0.5-\mathrm{cm}$ hole punch. These leaf disks were then dried at $60^{\circ} \mathrm{C}$ for 6 days before weighing using an analytical balance. LMA was measured for each plant in both common garden and reciprocal transplant experiments.

$R: S$. We measured the dry root mass per dry shoot mass (including leaves) for each individual at the end of the drydown experiment. We extracted each plant from the PVC tube and washed the sand and dirt away from the root system, with care taken to extract as much fine root matter as possible. Because complete root retrieval was time consuming and difficult, we standardized this process with a 20-min timed harvest of root biomass for each plant. After these timed harvests all root material $\geq 3 \mathrm{~mm}$ diameter had been harvested, as well as a large fraction of all remaining root material.

Analysis. We were primarily interested in the differences between the LOW and HIGH populations, therefore we performed two-way ANOvAs with genotype nested within population (HIGH or LOW) to test for significant differences between population means in both the field and laboratory studies. For the laboratory dry-down experiment we performed both repeated measures analysis on the complete (partially unbalanced) data set, and a more balanced ANOvA on a subset of the data, with each plant measured only once. DATADESK and SYSTAT were used for ANOvA, and differential survival at the two field sites was tested using the log-linear model procedure in SYSTAT.

\section{Expression profiling using cDNA-AFLP}

CDNA-AFLP analysis is a sensitive and reproducible technology that has a number of advantages over other methods for genome-wide expression analysis: it does not require prior sequence information, it allows the identification of novel genes, and it provides semiquantitative expression profiles (Volkmuth et al. 2003). We compared 5-month-old plants that had experienced the dry-down treatment to plants that had been well watered throughout their lives. Except for drought-stressed plants, most plants had already bolted or were in an early stage of flowering. For each treatment, leaf material from three (HIGH population) or four (LOW population) individual plants were pooled for RNA extraction. Three medium-aged leaves per plant were frozen in liquid nitrogen. Leaf material was ground to a fine powder in liquid $\mathrm{N}_{2}$, and total RNA was isolated using the TRIzol Reagent (Invitrogen, Carlsbad) according to the manufacturers' protocol. A second purification step was performed with RNAeasy columns (QIAGEN). An additional DNase treatment was included prior to the second purification step to eliminate any contaminating DNA. The DNase enzyme was inactivated according to the manufacturers' recommendations (Ambion). RNA integrity was verified on nondenaturing agarose gels. RNA quantity was determined photospectrometrically. cDNA-AFLP analysis was performed at Keygene as described by Volkmuth and colleagues (2003). Restriction enzymes employed TaqI/MseI with 256 primer combinations with two selective nucleotides on the TaqI site and three selective nucleotides on the MseI site. Bands of interest were excised, sequenced, and compared to Arabidopsis using BLAST. 
A

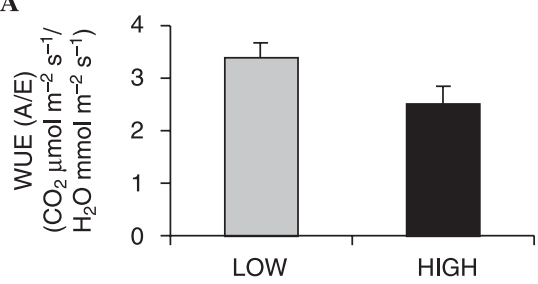

B

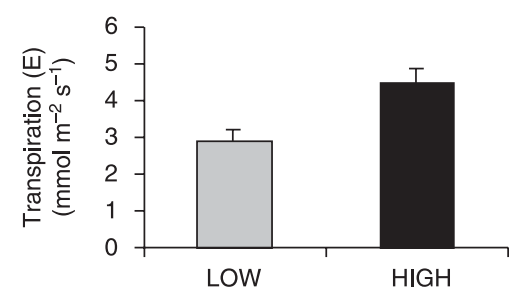

C

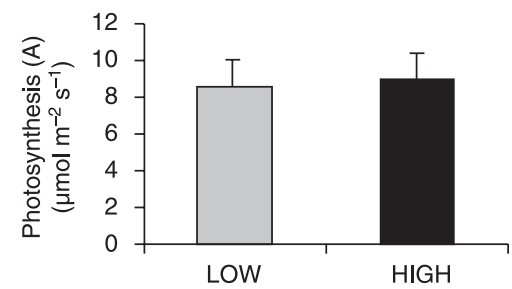

Fig. 2 Mean differences for water use efficiency (A), transpiration (B), and photosynthesis (C) for the LOW (grey bars) and HIGH (black bars) populations in the laboratory common garden experiment. These values are averages across the 29-day dry-down experiment. Differences for water use efficiency and transpiration were significant $(P<0.001$ by ANOvA). Photosynthesis was not significantly different between populations.

\section{Results}

\section{Common environment dry-down experiment}

Instantaneous WUE was significantly different between populations at the beginning of our dry-down experiment, and this difference was maintained throughout the experiment (Fig. 2). Repeated measures analysis of the entire data set and ANOvA on a balanced subset gave similar results. No significant genetic variation was found among families within populations $\left(F_{15,132}=1.11 ; P>0.05\right)$. The LOW population had significantly greater WUE and lower transpiration (both $P<0.002$ ). There was no significant difference between populations for photosynthesis $(P>$ $-0.05)$. Indeed, even when plants were well watered, LOW genotypes had higher WUE, suggesting that these plants cannot adopt a water-spending strategy similar to HIGH genotypes when water is available. Interestingly, populationmean WUE did not change significantly during the time course of this dry-down experiment (Fig. 3). This suggests that instantaneous WUE can be estimated under a variety of environmental conditions, and that WUE data may be a relatively stable quantitative trait, in contrast to photosynth-
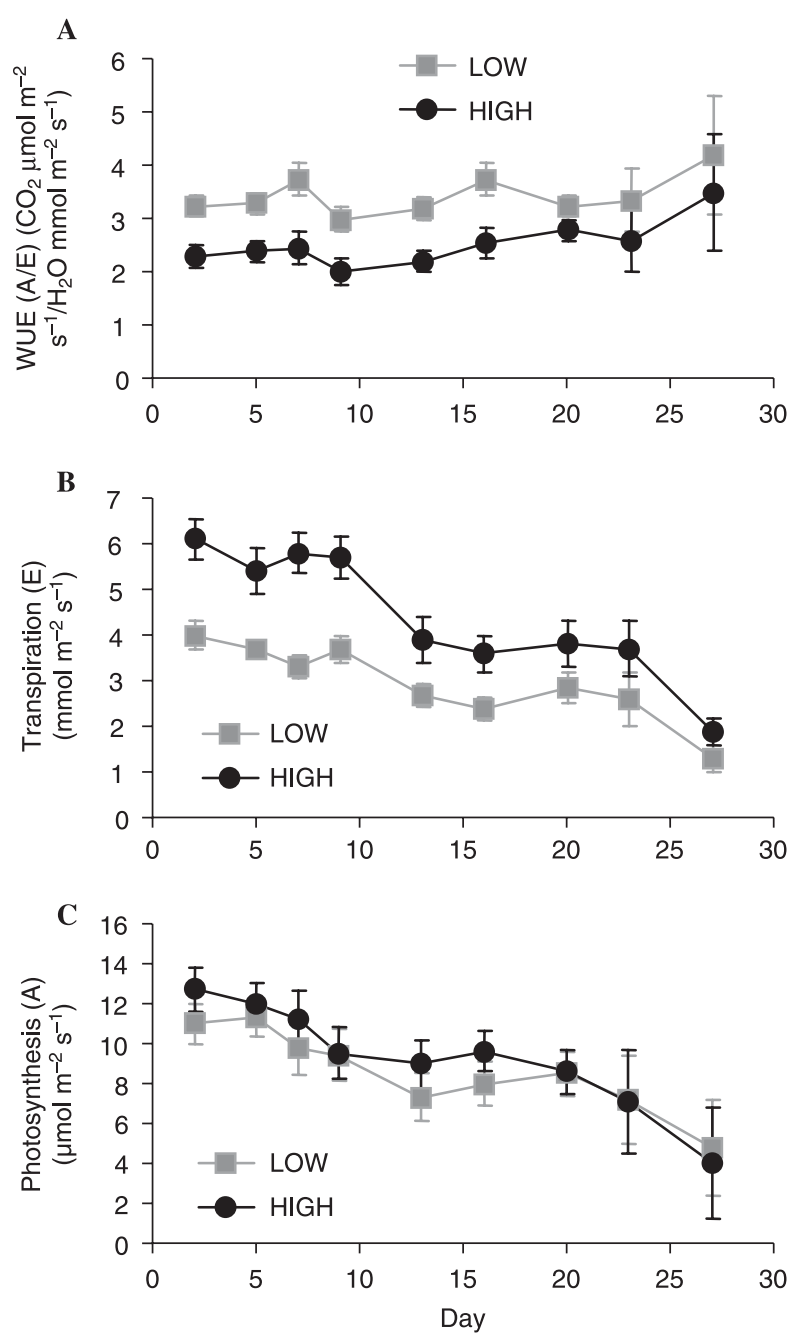

Fig. 3 Differences between LOW (grey squares) and HIGH (black circles) for water use efficiency (A), Transpiration (B) and photosynthesis (C) during the 29-day dry-down experiment in the laboratory. There was no significant difference between populations for photosynthesis. Error bars represent the standard error of the mean. Day 0 was the beginning of the experiment when the plants were well watered.

esis or transpiration, which are influenced by many environmental and developmental variables (e.g. Figs 2 and 3).

This experiment shows that the difference between populations for WUE was driven by a significant genetic difference between populations for transpiration rate (Figs 2 and 3). Photosynthesis did not differ significantly between populations. During the time course of the drydown experiment, both photosynthesis and transpiration declined substantially.

TDR probes in soil surrounding representative plants in our dry-down experiment indicate these dry-down conditions were very similar to drought in the field (Fig. 1). Note that the slope of the low end of the curve is similar between the dry-down and field data. The TDR data for the LOW 

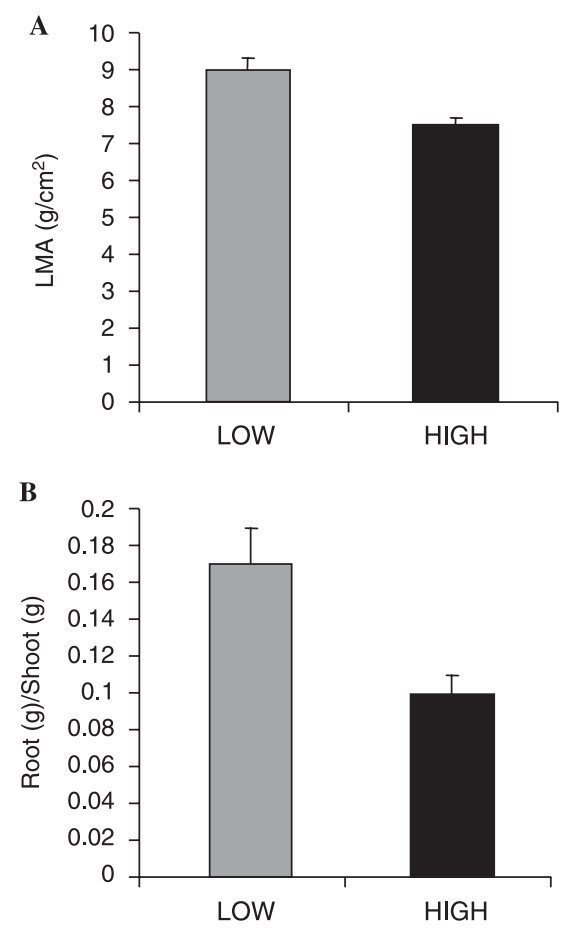

Fig. 4 The difference between LOW and HIGH populations for LMA before the start of the laboratory dry-down experiment and for root/shoot ratio after the dry-down.

and HIGH field sites also highlight some important environmental differences between these sites. In this sampling interval, precipitation affecting soil volumetric water content was much more frequent at the HIGH field site than at the LOW field site, even though they are in the same watershed, although at different elevations.

There was also a significant difference between LOW and HIGH genotypes for LMA and root/shoot ratios (Fig. $4 ; P<0.001$ by ANOvA). The LOW population had significantly greater LMA than HIGH genotypes, and developed a much more extensive root system, even though the plants were grown in the same environment.

\section{Reciprocal transplant experiment}

The reciprocal transplant experiment showed highly significant differential survival between HIGH and LOW populations at the two sites $\left(\chi^{2}=31.82\right.$, d.f. $\left.=1, P<0.0001\right)$. By August 2003 there were no surviving HIGH genotypes at the LOW field site. This difference in survival (especially the complete lack of HIGH genotype survival at the LOW field site) suggests adaptive ecotypic differentiation between these two populations. Due to the restricted sample size for LOW genotypes, only limited inferences can be made regarding the performance of LOW genotypes at the HIGH field site. However, of the 10 LOW individuals transplanted to the LOW site, 4 survived, whereas none of

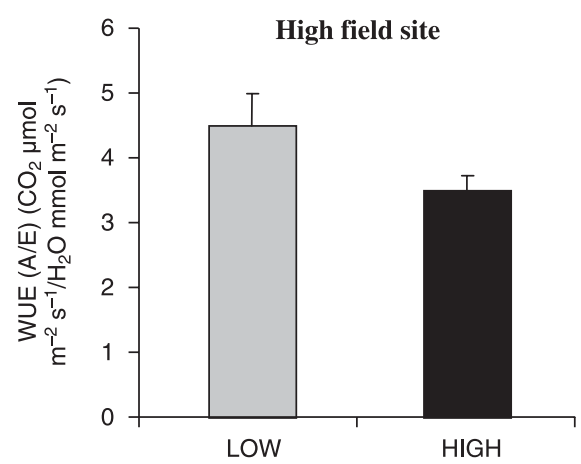

Fig. 5 Instantaneous WUE for LOW and HIGH plants at the HIGH field site. WUE was significantly greater for the LOW plants (grey bar) compared to the HIGH plants (black bar; see text for details). None of the HIGH plants survived at the LOW field site - so comparisons could not be made there.

the $75 \mathrm{HIGH}$ individuals survived at the low site. At the HIGH field site, 7 of the $10 \mathrm{LOW}$ plants survived, and 32 of 60 HIGH plants survived.

In August 2003 we measured instantaneous WUE for plants at the HIGH field site. WUE was significantly greater for the LOW plants compared to the HIGH plants (Fig. $5, F_{1,38}=3.67, P<0.05$ ). This field result corroborates the findings of our common garden dry-down experiment conducted in the laboratory. The magnitude of WUE values that we observed in the field fell within the same range of values that we observed in the laboratory experiment.

\section{CDNA-AFLPS}

Our CDNA-AFLP experiments identified candidate genes that may be differentially induced by drought in a wild relative of Arabidopsis. We pooled tissue samples from several plants to reduce variability, and compared genotypes from two locally adapted populations. Furthermore, these experiments identified a number of Boechera holboellii genes showing responses in accord with results from Arabidopsis (Table 1). Nevertheless, further experimentation is required to verify quantitative responses to drought by these candidate genes in B. holboellii, and to determine their possible functional role in drought tolerance.

Gene expression was inferred on cDNA-AFLP gels using a visual scale ranging from 0 (no expression) to 3 (strong expression; see Table S1, Supplementary material). Genes up-regulated by drought included homologues of the following Arabidopsis loci: At5g49330, an MYB family transcription factor; At5g13170, a nodulin protein similar to MtN3; as well as At5g15250, which is similar to FtsH-like protein. We also identified drought-induced homologues of two Arabidopsis expressed proteins (At5g53660 and At5g63350), whose functions are unknown in Arabidopsis. Finally, homologues of At2g27420 (a putative cysteine 
Table 1 Boechera holboellii genes showing responses to drought treatment as predicted by water stress experiments in Arabidopsis

\begin{tabular}{ll}
\hline Gene name & $\begin{array}{l}\text { Arabidopsis } \\
\text { locus }\end{array}$ \\
\hline $\begin{array}{l}\text { leucine-rich repeat transmembrane protein kinase } \\
\text { dehydrin (COR47) }\end{array}$ & At1g09970 \\
late embryogenesis abundant protein (LEA 76) & At1g20440 \\
AAA-type ATPase & At1g52690 \\
alcohol dehydrogenase (ADH) & At1g64110 \\
zinc finger homeobox family protein & At1g77120 \\
cold-responsive protein (cor15a) & At2g02540 \\
galactinol synthase & At2g42540 \\
ATPase, plasma membrane-type & At2g47180 \\
zinc finger (DHHC type) family protein & At3g47950 \\
homeobox-leucine zipper protein 12 (HB-12) & At3g48760 \\
dehydration-responsive protein ERD3 & At3g61890 \\
myb family transcription factor (MYB29) & At5g06050 \\
sugar transporter, putative similar to ERD6 protein & At5g07690 \\
myb family transcription factor & At5g37840 \\
LTI78/desiccation-responsive protein 29A (RD29A) & At5g52310 \\
ABA-responsive protein (HVA22b) & At5g62490 \\
\hline
\end{tabular}

proteinase) and At5g49360 (a glycosyl hydrolase family 3 protein) were down-regulated by drought.

Next, we identified genes that are capable of high expression in both HIGH and LOW populations (which ensures effective primer binding in both populations), but which show population-specific differences in expression depending on water availability. Chief among these was a homologue of At5g40880, a WD-40 repeat family protein/ zfwd3 like-protein, which was more induced in the LOW population under drought conditions.

\section{Discussion}

We examined the physiological basis of local adaptation to drought stress in a perennial relative of Arabidopsis thaliana and used cDNA-AFLPs to identify candidate genes showing differential expression in response to moisture availability. These populations are separated by an elevation difference of $1450 \mathrm{~m}$ and showed a large difference in soil moisture, with higher moisture levels at the higher elevation. Reciprocal transplant experiments between the field populations showed that genotypes have significantly higher survival in their native habitat. Genotypes from the dryer site had higher WUE, which was attributable to a $30 \%$ reduction in transpirational water loss. However, there was no genetic difference for photosynthetic rate between populations. The drier, low-elevation population also had thicker leaves and increased investment in root biomass.

Analysis of cDNA-AFLPs identified candidate genes associated with physiological responses to drought. A number of loci showed response patterns concordant with patterns in Arabidopsis (Kirch et al. 2005). For example, homologues of dehydrin, ERD3 dehydration-responsive protein, RD29A desiccation-responsive protein, an ABAresponsive protein, and several transcription factors are up-regulated by water stress in Arabidopsis and Boechera holboellii. Several findings also extend previous results from Arabidopsis. We found, for example, several droughtinduced genes of unknown function, as well as a WD-40 repeat protein, which shows population-specific induction patterns in response to water availability. Also of interest are the pentatricopeptide (PPR) repeat-containing proteins that we identified as being differentially expressed in these populations. They act as central switches for RNA editing and RNA metabolism in the chloroplasts (SchmitzLinneweber et al. 2005). To our knowledge these proteins have not previously been associated with responses to drought. These candidate genes can now be used to verify inferred expression patterns and to examine possible functional roles in drought tolerance.

Genetic variation for WUE and related traits has been documented in a number of species (e.g. Dudley 1996a, b; Geber \& Dawson 1997; Sandquist \& Ehleringer 2003a, b; Condon et al. 2004). Early studies of heritable variation for WUE have been reviewed by Ackerly et al. (2000) and Arntz \& Delph (2001). More recently, Caruso et al. (2005) examined genetic constraints on photosynthetic and water use traits in two Lobelia species. High levels of quantitative genetic variation were observed in Lobelia siphilitica, and lower levels in Lobelia cardinalis. Rates of carbon assimilation and water loss were genetically independent within both species. However, plant growth and WUE showed significant negative genetic correlation in L. siphilitica, suggesting a physiological and genetic cost to high WUE. In addition, Heschel and colleagues (2002 2005) found contrasting patterns of natural selection in Impatiens capensis, depending on early vs. late onset of drought stress. Natural selection favoured drought avoidance (early flowering, increased stomatal conductance, and decreased WUE) under early season water stress, whereas late-season drought favoured higher WUE. Thus, strategies of drought avoidance or drought tolerance may be favoured in different populations and years, depending on local climate.

Several studies have documented genetic variation for WUE in Arabidopsis. McKay et al. (2003) found significant genetic variation for WUE among Arabidopsis ecotypes, and evidence for a genetic trade-off between WUE and drought avoidance via early flowering. Recently Hausmann et al. (2005) mapped quantitative trait loci influencing WUE and found genotype-environment interaction in response to water availability. In two species of Boechera, McKay et al. (2001) found adaptive, genetically based differences across a gradient of water availability. In Boechera fecunda, lowelevation genotypes had greater WUE, as well as morphological differences in root/shoot ratio and leaf characteristics. 
These evolutionary responses to moisture and elevation gradients in Boechera species are consistent and predictable, and have been independently verified in the present study. Positional cloning of ecologically important genetic polymorphisms is now feasible in this close wild relative of Arabidopsis.

Genetic variation between mesic and drought-prone populations for LMA and R:S is well known (Fitter \& Hay 2002). However, the molecular basis of differences in these complex traits has not been established. The candidate genes (Table S1) that we identified by cDNA-AFLPs may be useful in future studies of this ecologically important trait variation (e.g. Wright et al. 2004).

\section{Acknowledgements}

We thank Carol Eunmi Lee and four anonymous reviewers for helpful comments on the manuscript. This work was supported by grant DEB 9527725 from the US National Science Foundation, by grant QRLT-2000-01097 from the European Union, and by the Max-Planck Gesellschaft.

\section{References}

Abe H, Urao T, Ito T et al. (2003) Arabidopsis AtMYC2 (bHLH) and AtMYB2 (MYB) function as transcriptional activators in abscisic acid signaling. Plant Cell, 15, 63-494.

Abrams M, Kubiske M, Mostoller S (1994) Relating wet and dry year ecophysiology to leaf structure in contrasting temperate tree species. Ecology, 75, 123-133.

Ackerly DD, Dudley SA, Sultan SE et al. (2000) The evolution of plant ecophysiological traits: recent advances and future directions. Bioscience, 50, 979-995.

Al-Shehbaz IA (2003) Transfer of most North American species of Arabis to Boechera (Brassicaceae). Novon, 13, 381-391.

Arntz AM, Delph LF (2001) Pattern and process: evidence for the evolution of photosynthetic traits in natural populations. Oecologia, 127, 455-467.

Bartels D, Sunkar R (2005) Drought and salt tolerance in plants. Critical Reviews in Plant Sciences, 24, 23-58.

Bohnert HJ, Nelson DE, Jensen RG (1995) Adaptations to environmental stresses. Plant Cell, 7, 1099-1111.

Boyce JM, Knight H, Deyholos M et al. (2003) The sfr6 mutant of Arabidopsis is defective in transcriptional activation via CBF/ DREB1 and DREB2 and shows sensitivity to osmotic stress. Plant Journal, 34, 395-406.

Bray E (1997) Plant responses to water deficit. Trends in Plant Science, 2, 48-54.

Bray EA (2004) Genes commonly regulated by water-deficit stress in Arabidopsis thaliana. Journal of Experimental Botany, 55, 2331-2341.
Carlson PS (1980) The Biology of Crop Productivity. Academic Press, New York.

Caruso CM, Maherali H, Mikulyuk A, Carlson K, Jackson RB (2005) Genetic variance and covariance for physiological traits in Lobelia: are there constraints on adaptive evolution? Evolution, 59, 826-837.

Chaves M, Maroco J, Pereira J (2003) Understanding plant responses to drought - from genes to the whole plant. Functional Plant Biology, 30, 239-264.

Cheong YH, Kim K-N, Pandey GK et al. (2003) CBL1, a calcium sensor that differentially regulates salt, drought, and cold responses in Arabidopsis. Plant Cell, 15, 1833-1845.

Clausen J, Heisey W (1958) Experimental studies on the nature of species IV. Genetic structure of ecological races. In: Carnegie Institution of Washington Publication, 615. Carnegie Institute, Washington D.C.

Condon AG, Richards RA, Rebetzke GJ, Farquhar GD (2004) Breeding for high water-use efficiency. Journal of Experimental Botany, 55, 2447-2460.

Dobes C, Mitchell-Olds T, Koch MA (2004a) Intraspecific diversification in North American Boechera stricta (= Arabis drummondii), Boechera xdivaricarpa, and Boechera holboellii (Brassicaceae) inferred from nuclear and chloroplast molecular markers - an integrative approach. American Journal of Botany, 91, 2087-2101.

Dobes CH, Mitchell-Olds T, Koch MA (2004b) Extensive chloroplast haplotype variation indicates Pleistocene hybridization and radiation of North American Arabis drummondii, A. divaricarpa, and A. holboellii (Brassicaceae). Molecular Ecology, 13, 349-370.

Dudley SA (1996a) Differing selection on plant physiological traits in response to environmental water availability: a test of adaptive hypotheses. Evolution, 50, 92-102.

Dudley SA (1996b) The response to differing selection on plant physiological traits: evidence for local adaptation. Evolution, 50, 103-110.

Feder M, Mitchell-Olds T (2003) Evolutionary and ecological functional genomics. Nature Reviews Genetics, 4, 651-657.

Fitter A, Hay R (2002) Environmental Physiology of Plants. Academic Press, San Francisco, California.

Geber M, Dawson T (1997) Genetic variation in stomatal and biochemical limitations to photosynthesis in the annual plant, Polygonum arenastrum. Oecologia, 109, 535-546.

Givnish TJ (1979) On the adaptive significance of leaf form. In: Topics in Plant Population Biology (eds Solbrig OT, Jain S, Johnson GB, Raven PH), pp. 375-407. Columbia University Press, New York.

Hamilton MB, Mitchell-Olds T (1994) The mating system and relative performance of selfed and outcrossed progeny in Arabis fecunda (Brassicaceae). American Journal of Botany, 81, 1252-1256.

Harlan H, Martini M (1938) The effects of natural selection in a mixture of barley varieties. Journal of Agricultural Research, 57, 189-199.

Hausmann NJ, Juenger TE, Sen S et al. (2005) Quantitative trait loci affecting delta C-13 and response to differential water availability in Arabidopsis thaliana. Evolution, 59, 81-96.

Heschel MS, Riginos C (2005) Mechanisms of selection for drought stress tolerance and avoidance in Impatiens capensis (Balsaminaceae). American Journal of Botany, 92, 37-44.

Heschel MS, Donohue K, Hausmann N, Schmitt J (2002) Population differentiation and natural selection for water-use efficiency in Impatiens capensis (Balsaminaceae). International Journal of Plant Sciences, 163, 907-912.

Jordan N (1991) Multivariate analysis of selection in experimental populations derived from hybridization of two ecotypes of the annual plant Diodia teres W. (Rubiaceae). Evolution, 45, 1760-1772. 
Kawaguchi R, Girke T, Bray E, Bailey-Serres J (2004) Differential mRNA translation contribute to gene regulation under nonstress and dehydration stress conditions in Arabidopsis thaliana. Plant Journal, 38, 823-839.

Kirch H-H, Schlingensiepen S, Kotchoni S, Sunkar R, Bartels D (2005) Detailed expression analysis of selected genes of the aldehyde dehydrogenase $(A L D H)$ gene superfamily in Arabidopsis thaliana. Plant Molecular Biology, 57, 315-332.

Koch MA, Dobes C, Mitchell-Olds T (2003) Multiple hybrid formation in natural populations: concerted evolution of the internal transcribed spacer of nuclear ribosomal DNA (ITS) in North American Arabis divaricarpa (Brassicaceae). Molecular Biology and Evolution, 20, 338-350.

Kreps JA, Wu Y, Chang H-S et al. (2002) Transcriptome changes for Arabidopsis in response to salt, osmotic, and cold stress. Plant Physiology, 130, 2129-2163.

McKay JK, Bishop JG, Lin JZ et al. (2001) Local adaptation across a climatic gradient despite small effective population size in the rare sapphire rockcress. Proceedings of the Royal Society of London. Series B, Biological Sciences, 268, 1715-1721.

Mckay JK, Richards JH, Mitchell-Olds T (2003) Genetics of drought adaptation in Arabidopsis thaliana. I. Pleiotropy contributes to genetic correlations among ecological traits. Molecular Ecology, 12, 1137-1151.

Mitchell-Olds T (2001) Arabidopsis thaliana and its wild relatives: a model system for ecology and evolution. Trends in Ecology E Evolution, 16, 693-700.

Mitchell-Olds T, Al-Shehbaz I, Koch M, Sharbel T (2005) Crucifer evolution in the post-genomic era. In: Diversity and Evolution of Plants - Genotype and Phenotype Variation in Higher Plants (ed. Henry R), pp. 119-137. CABI Press, Cambridge, Massachusetts.

Nagy E (1997) Selection for native characters in hybrids between two locally adapted plant subspecies. Evolution, 51, 1469-1480.

Nobel P (1974) Introduction to Biophysical Plant Physiology. W.H. Freeman, San Francisco, California.

Oh S-J, Song SI, Kim YS et al. (2005) Arabidopsis CBF3/DREB1A and $\mathrm{ABF} 3$ in transgenic rice increased tolerance to abiotic Stress without stunting growth. Plant Physiology, 138, 341-351.

Oono Y, Seki M, Nanjo T et al. (2003) Monitoring expression profiles of Arabidopsis gene expression during rehydration process after dehydration using ca. 7000 full-length cDNA microarray. Plant Journal, 34, 868-887.

Raschke K (1976) How stomata resolve the dilemma of opposing priorities. Philosophical Transactions of the Royal Society of London. Series B, Biological Sciences, 273, 551-560.

Reymond P, Weber H, Damond M, Farmer EE (2000) Differential gene expression in response to mechanical wounding and insect feeding in Arabidopsis. Plant Cell, 12, 707-720.

Rhoades JD, Raats PAC, Prather RJ (1976) Effects of liquid-phase electrical conductivity, water content, and surface conductivity on bulk soil electrical conductivity. Soil Sci Ass Am J, 40, 651-653.

Rhoades JD, Manteghi NA, Shouse PJ, Alves WJ (1989) Soil electrical conductivity and soil salinity: new formulations and calibrations. Soil Science Society of America Journal, 53, 433-439.

Rizhsky L, Liang H, Shuman J et al. (2004) When defense pathways collide. The response of Arabidopsis to a combination of drought and heat stress. Plant Physiology, 134, 1683-1696.

Rollins RC (1993) The Cruciferae of Continental North America. Stanford University Press, Stanford, California.

Roy BA (1996) A plant pathogen influences pollinator behavior and may influence reproduction of nonhosts. Ecology, 77, 2445-2457.
Roy BA (2001) Patterns of association between crucifers and their flower-mimic pathogens: host jumps are more common than coevolution or cospeciation. Evolution, 55, 41-53.

Sandquist DR, Ehleringer JR (2003a) Carbon isotope discrimination differences within and between contrasting populations of Encelia farinosa raised under common-environment conditions. Oecologia, 134, 463-470.

Sandquist DR, Ehleringer JR (2003b) Population- and family-level variation of brittlebush (Encelia farinosa, Asteraceae) pubescence: its relation to drought and implications for selection in variable environments. American Journal of Botany, 90, 1481-1486.

Schemske DW (1984) Population structure and local selection in Impatiens pallida (Balsaminaceae), a selfing annual. Evolution, 38, 817-832.

Schmitz-Linneweber C, Williams-Carrier R, Barkan A (2005) RNA immunoprecipitation and microarray analysis show a chloroplast pentatricopeptide repeat protein to be associated with the $5^{\prime}$ region of mRNAs whose translation it activates. Plant Cell, 17, 2791-2804.

Schranz M, Dobes D, Koch M, Mitchell-Olds T (2005) Sexual reproduction, hybridization, apomixis and polyploidization in the genus Boechera (Brassicaceae). American Journal of Botany, 97, 17971810.

Sharbel TF, Mitchell-Olds T (2001) Recurrent polyploid origins and chloroplast phylogeography in the Arabis holboellii complex (Brassicaceae). Heredity, 87, 59-68.

Sharbel T, Voigt M, Mitchell-Olds T, Kantama L, de Jong H (2004) Is the aneuploid chromosome in an apomictic Boechera holboellii a genuine B chromosome? Cytogenetic and Genome Research, 106, 173-183.

Shrantz J, Piemesal L (1927) The water requirements at Akron, Colorado. Journal of Agriculture Research, 34, 10931190.

Stebbins G (1952) Aridity as a stimulus to plant evolution. American Naturalist, 86, 33-44.

Taskin KM, Turgut K, Ercan AG, Scott RJ (2003) Agrobacteriummediated transformation of Arabis gunnisoniana. Plant Cell, Tissue, and Organ Culture, 72, 173-179.

Thomas MA, Klaper R (2004) Genomics for the ecological toolbox. Trends in Ecology \& Evolution, 19, 439-445.

Volkmuth W, Turk S, Shapiro A et al. (2003) Technical advances: genome-wide cDNA-AFLP analysis of the Arabidopsis transcriptome. OMICS, 7, 143-159.

Wright I, Cannon K (2001) Relationships between leaf lifespan and structural defenses in a low-nutrient, sclerophyll flora. Functional Ecology, 15, 351-359.

Wright I, Reich P, Westoby M et al. (2004) The worldwide leaf economics spectrum. Nature, 428, 821-827.

Charles Knight is Assistant Professor at California Polytechnic State University with interests in plant physiological ecology. Heiko Vogel and Juergen Kroymann are research group leaders studying plant-insect interactions at the Max Planck Institute for Chemical Ecology. Alice Shumate is an Assistant Professor at Fairleigh Dickinson University studying evolutionary dynamics of plant-insect interactions. Hanneke Witsenboer is a molecular biologist at Keygene. Thomas Mitchell-Olds is Professor of Biology at Duke University studying evolutionary and ecological functional genomics. 